\title{
Rare Shewanella spp. associated with pulmonary and bloodstream infections of cancer patients, China: a case report
}

\author{
Furong Zhang ${ }^{1 \dagger}$, Yujie Fang ${ }^{2,3,4+}$, Feng Pang ${ }^{5,6+}$, Shengnan Liang ${ }^{1}$, Xin Lu ${ }^{2,3}$, Biao Kann ${ }^{2,3}$, Jianguo Xu $\mathrm{u}^{2,3}$, \\ Jinxing Zhao ${ }^{1}$, Yinju Du ${ }^{1 *}$ and Duochun Wang ${ }^{2,3,4^{*}}$
}

\begin{abstract}
Background: Members of Shewanella species are opportunistic pathogens that are found in marine environments. Currently more than sixty species have been identified, whereas the most commonly clinical cases associated with Shewanella species have involved only two species, i.e., S. algae and S. putrefaciens. We present two cases of pulmonary and bloodstream infections caused by two rare Shewanella spp. strains from patients of gastrointestinal cancer.

Case presentation: Two male patients with a history of gastrointestinal cancer presented to hospital with pulmonary and bloodstream infections, respectively. The infective pathogens of both cases were primarily isolated and identified as Shewanella algae (case I) and Shewanella putrefaciens (case II) by phenotypic features and VITEK 2 system, but they were further confirmed as Shewanella haliotis and Shewanella upenei by 165 rRNA gene sequence analysis. The major bacterial composition of the bronchoalveolar lavage in case I was also identified as Shewanella by 165 rRNA amplicon sequencing analysis. Antimicrobial susceptibility testing showed that the two strains had broad susceptibility, but $\mathrm{S}$. haliotis in the case I was resistant to ciprofloxacin and levofloxacin and S. upenei in the case || was intermediate to imipenem, piperacillin/ tazobactam and ciprofloxacin.

Conclusions: To the best of our knowledge, this is the first cases of the pulmonary and bloodstream infections caused by Shewanella spp. from clinical patients in mainland China. Shewanella as a potential pathogen in China should not be ignored.
\end{abstract}

Keywords: Rare Shewanella spp., Pulmonary and bloodstream infections, Cancer patients, China

\section{Background}

The genus Shewanella comprises members of Gram-negative, motile, oxidase-positive, facultative anaerobic and motile rods. Bacteria are widely distributed in nature, mainly in marine environment. Currently the genus composes of more than sixty species (http://www.bacterio.net/shewanella.html); among them, four species have been reported to cause human infections, i.e., Shewanella putrefaciens, Shewanella algae, Shewanella haliotis [1]

\footnotetext{
* Correspondence: Iccdcdyj@126.com; wangduochun@icdc.cn

${ }^{\dagger}$ Furong Zhang, Yujie Fang and Feng Pang contributed equally to this work.

'Liaocheng Center for Disease Control and Prevention, Liaocheng, People's Republic of China

${ }^{2}$ State Key Laboratory of Infectious Disease Prevention and Control, National Institute for Communicable Disease Control and Prevention, Chinese Center for Disease Control and Prevention, Beijing 102206, People's Republic of China

Full list of author information is available at the end of the article
}

and Shewanella xiamenensis [2], whereas the most commonly clinical cases associated with Shewanella species have involved only two species, i.e., S. algae and S. putrefaciens [3]. In this study, we identified S. haliotis and $S$. upenei strains isolated from pulmonary tissue infection and bacteremia of clinical patients in Liaocheng, an inland city in China. Those are first reported cases of pulmonary and bloodstream infections caused by Shewanella spp. in mainland China. Our study suggests that Shewanella spp. is a potential opportunistic pathogen which should not be ignored even outside coastal regions.

\section{Case presentation}

Case 1

A esophageal cancer patient who was diagnosed as $S$. haliotis pulmonary inflammation. 
A 68-year-old male patient was admitted to people's hospital of Liaocheng city, China, on July 24, 2016, because of "hematemesis for 4 hours". He had been diagnosed with the operation of esophageal cancer for more than 2 years. His admitted physical examinations were body temperature of $36.3{ }^{\circ} \mathrm{C}$, pulse rate 92 beats/min, breathing of 22 times/min and blood pressure 135/ $80 \mathrm{mmHg}$. Nonpalpable enlargement of bilateral neck and supraclavicular lymph nodes, trachea in the middle, pectoral symmetry, visible scars at right chest, clear percussion sound at double lung, auscultation of coarse breath sound, no dry and wet rales, regular rhythm, percussion no pain of the kidney area, negative for shifting dullness and bowel sounds of 3 times/min. His admission diagnosis was esophageal cancer after operation and hypertension. On admission, the auxiliary examinations were performed to determine the source of hematemesis. The painless gastroscopy was carried out, but no obvious abnormalities was observed. The painless bronchoscopic examination revealed posterior basal segment of left lower lobe hemorrhage. Brushing pathology indicated no obvious tumor cells. Thoracic and abdominal enhanced computed tomography scan showed that he had esophageal surgery, bronchitis and emphysema, middle lobe of right lung nodules, right upper lobe and left lower lobe interstitial lesions and the lower lobe of the left lung inflammation. He was given medicine (3 $\mathrm{g}$ of cefoperazone/sulbactam was administrated twice a day for 6 days) and therapy of anticancer, anti-inflammatory, rehydration and hemostasis. After six days' treatment, his symptoms improved and the patient was discharged from the hospital.

The bronchoalveolar lavage fluid (BALF) was collected when he received painless bronchoscopic examination and the cell number was over $10^{4} \mathrm{cfu} / \mathrm{ml}$. Sample was streak-inoculated on blood agar medium for bacterial culture. Strains of different phenotypic features at blood plates were isolated and identified as S. algae, Escherichia coli and Klebsiella pneumoniae by VITEK 2 system using the ID-GN card (boiMérieux). Since only two Shewanella species, S. putrefaciens and S. algae, were registered in the database of VITEK 2 system, the 16S rRNA gene sequence was amplified by a PCR described previously [4]. The PCR product was sequenced and the nucleotide sequence had been deposited at GenBank, under the accession number of MF589233. BLAST analysis of $16 \mathrm{~S}$ rRNA gene sequence at GenBank showed a similarity of $99.0 \%$ with type strain of $S$. haliotis DW01 (accession numbers NR_117770.1). Further phylogenetic analysis with all type sequences of Shewanella species available in the GenBank database, confirmed the strain was identified as species of S. haliotis (LC2016-1 in Fig. 1).

To further confirm the bacterial community composition and richness of the BALF, sample was subjected to the $16 \mathrm{~S}$ rRNA amplicon sequencing $[5,6]$. The result indicated the bacterial community composition included genera of Shewanella (88.34\%), Escherichia (11.11\%) and Streptococcus $(0.38 \%)$, et al., whereas the majority of genus was Shewanella.

Antibiotic susceptibility testing was performed by microdilution method on Mueller-Hinton broth. The strain was susceptible to piperacillin/tazobactam (minimal inhibitory concentration, MIC: $8 \mu \mathrm{g} / \mathrm{ml}$ ), ceftazidime $(1 \mu \mathrm{g} / \mathrm{ml})$, cefepime $(1 \mu \mathrm{g} / \mathrm{ml})$, amikacin $(2 \mu \mathrm{g} / \mathrm{ml})$, gentamicin $(1 \mu \mathrm{g} / \mathrm{ml})$, imipenem $(4 \mu \mathrm{g} / \mathrm{ml})$, meropenem $(4 \mu \mathrm{g} / \mathrm{ml})$, but was resistant to ciprofloxacin $(8 \mu \mathrm{g} / \mathrm{ml})$ and levofloxacin $(8 \mu \mathrm{g} / \mathrm{ml})$.

\section{Case 2}

A gastric cancer patient who was diagnosed as S. algae bacteremia.

A 56-year-old man was admitted to people's hospital of Liaocheng city, China, on 6, Oct. 2016, because of "discomfort of upper abdominal pain for 1 month". His admitted physical examination included body temperature of 36.1 degrees, pulse rate of 72 beats/min, breathing 18 times/min and blood pressure 140/90 mmHg. Detection of nonpalpable enlargement of bilateral neck and supraclavicular lymph nodes, flat abdomen, no gastrointestinal or peristaltic waves were observed. Soft abdominal muscles, mild tenderness in the upper abdomen and no obvious rebound pain were reported. His liver and spleen did not touch under the rib and no palpable mass was discovered. Negative for shifting dullness, normal bowel sounds and no abnormal of rectal examination were detected. The gastroscope suggested visible ulcer lesions at the cardiac involving gastric fundus and gastric body. The pathological results indicated adenocarcinoma. His admission diagnoses were gastric cancer and hypertension.

On admission, the auxiliary examination were carried out on Oct. 9, 2016. Laparoscopy indicated he was in the late stage tumors without radical resection. He then received intravenous and intraperitoneal chemotherapy, followed by severe bone marrow suppression with blood cells and platelets significantly lower than normal. He was given further treatment of anti infection, nutritional support, rehydration, stimulating granulopoiesis and symptomatic treatment. On Oct. 26, 2016, patients had shortness of breath, heart rate and other symptoms with lung breath sounds rough, and no rales, limbs cold. He was considered the existence of septic shock. He was given non-invasive mechanical ventilation and fluid expansion, colloid, blood transfusion products, anti infection ( $1 \mathrm{~g}$ of imipenem was administrated every $8 \mathrm{~h}$ for 7 days), maintain circulation, acid suppression, liver protection, nutritional support, maintenance of water and electrolyte acid-base balance, monitoring blood pressure, heart rate, respiratory function, hour urine volume and bleeding. Patient had severe infection, and the presence of 


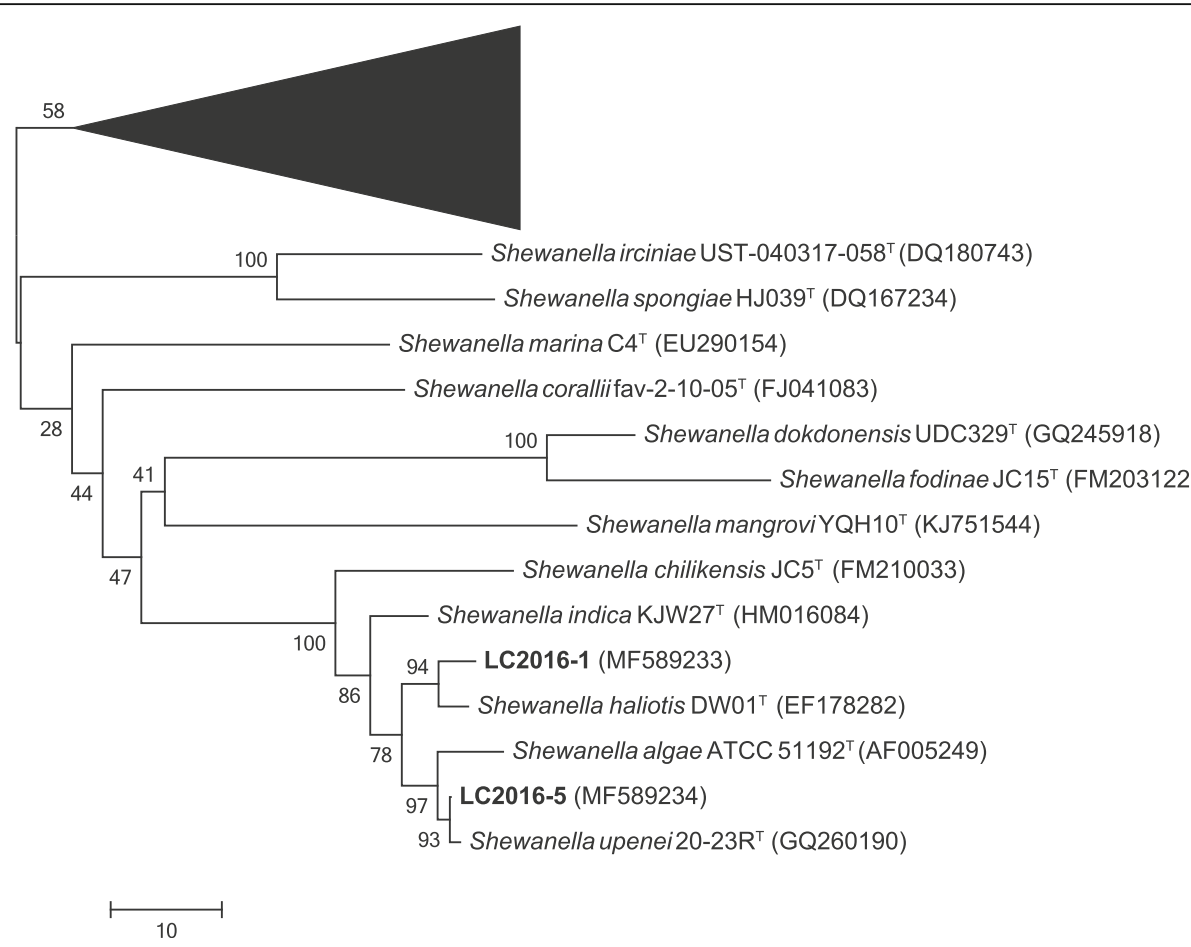

Fig. 1 Phylogenetic tree constructed by the neighbour-joining method based on the nucleotide sequences of the 16S rRNA gene. The phylogenetic tree was constructed from an alignment of 1427 nt and all known type strains of the Shewanella species were included. Numbers at nodes indicated bootstrap values (percentage of 1000 replicates). Bar, 10 substitutions per nucleotide position. Bold font indicated the strains from case I and II. GenBank accession numbers of $16 \mathrm{~S}$ rRNA gene sequences were in brackets. The black triangle consisted of fifty-four Shewanella species. Species names and GenBank accession numbers of 16S rRNA gene sequences were listed in Additional file 1: Table S1

multiple organ dysfunction syndrome (breathing, circulation, gastrointestinal, blood and kidney). Patient and his family members required automatic discharge for hospice care. His discharge diagnoses were multiple organ dysfunction syndrome (respiratory, circulatory, gastrointestinal, blood and kidney), gastric cancer and hypertension.

After appearing septic shock, his blood culture was sampled to separate the bacteria. The microbial growth was detected in both anaerobic and aerobic bottles and the positive reported time were 8.1 and $11.9 \mathrm{~h}$, respectively. Both bottles yielded an uniform Gram-negative bacillus. After $24 \mathrm{~h}$ incubation, haemolytic, oxidasepositive yellow colonies grew on blood agar. The strain was identified as $S$. putrefaciens by VITEK 2 system using the ID-GN card (boiMérieux). The 16S rRNA gene sequence of the strain had been deposited at GenBank (accession number: MF589234). BLAST analysis at GenBank showed a similarity of $100.0 \%$ with S. upenei strain VITVAGJ (accession numbers KP090164.1). Further phylogenetic analysis with all type sequences of Shewanella species available in the GenBank database, confirmed the strain belonged to species of $S$. upenei (LC2016-5 in Fig. 1). On the day of blood sampling, his peritoneal drainage fluid was also collected and cultured using the same identification methods, and the results of bacterial identification and drug sensitivity were consistent with that of blood.

Antibiotic susceptibility testing was performed by microdilution method on Mueller-Hinton broth. The strain was susceptible to aztreonam $(1 \mu \mathrm{g} / \mathrm{ml})$, ceftazidime $(1 \mu \mathrm{g} / \mathrm{ml})$, cefepime $(1 \mu \mathrm{g} / \mathrm{ml})$, amikacin $(2 \mu \mathrm{g} / \mathrm{ml})$, gentamicin $(1 \mu \mathrm{g} / \mathrm{ml})$ and levofloxacin $(1 \mu \mathrm{g} / \mathrm{ml})$, but was intermediate to imipenem $(8 \mu \mathrm{g} / \mathrm{ml})$, piperacillin/ tazobactam $(64 \mu \mathrm{g} / \mathrm{ml})$ and ciprofloxacin $(2 \mu \mathrm{g} / \mathrm{ml})$.

\section{Discussion and conclusions}

In this study, we reported the pulmonary and bloodstream infections caused by two rare Shewanella spp. from clinical patients in mainland China. In humans, the majority of Shewanella-associated syndromes involves the skin and soft-tissue infections [7-9], followed by bloodborne illnesses [10] and infections of the biliary tree $[11,12]$. In recent years, Shewanella has also been reported to be associated with food poisoning [13]. Diseases associated with the respiratory tract are rare and Shewanella strains have been recovered from sputum of a patient with chronic obstructive airway disease [14], a lung aspirate of a patient with lung tumor [15] and BALF specimens of two patients with ventilator-associated pneumonia [16, 17]. In additional, Shewanella have also been thought to 
play important roles in other cases of empyema or pneumonia [14, 18]. However, among all above cases, multi-pathogens were isolated from the same samples, making the exact role of each organism played in the pathogenicity unclear. In this study of case 1 , by $16 \mathrm{~S}$ rRNA amplicon sequencing, we identified the majority of bacterial community composition of the BALF was Shewanella, which strongly suggested that Shewanella as the primary pathogen might play a significant contributory role in the pulmonary infection.

Four Shewanella species have been confirmed the relevance to clinical infections, i.e., S. algae, S. putrefaciens, S. haliotis [1] and S. xiamenensis [2]. Species of S. haliotis was first isolated from the gut microflora of abalone in 2007 [19]. Patients associated with S. haliotis infection cases have been reported in Japan [20], Thailand [1] and Spain [21]. Cases are involved in phlegmonous inflammation as well as severe soft tissue infections from legs and cellulitis. In this study, the etiology of infection in the case 1 was identified as $S$. haliotis and our report is the first pulmonary infection associated with $S$. haliotis from patient of gastrointestinal cancer from inland city, China. Meanwhile, bloodstream infection associated with Shewanella strains have involved only two species, i.e., $S$. algae [10, 22, 23] and S. putrefaciens [8, 24]. Species of $S$. upenei was isolated from intestine of bensasi goatfish in 2011 [25], and there have been no report of clinical infection related to S. upenei. Our study of case 2 is the first reported of bloodstream infection associated with this rare Shewanella species, which was isolated from clinical patient.

Geographically, countries and regions that have reported clinical infections of Shewanella include Southeast Asia, Southern Europe, and South Africa. In Asia, Shewanel$l a$-associated infections have been reported in Thailand [1], Japan [26] and Taiwan [11] of China. Risk factors of human infections attributed to the genus Shewanella occur in warmer climates. The majority of cases occurs in coastal areas and most are related to exposure to Shewanella species present in seawater and seafood [27]. Shewanella illnesses are also typically found in middle-aged to older persons [12]. In this study, the two cases occurred in July and October at Liaocheng, an inland city in China and our retrospective survey reveals the two patients did not establish contact with coastal areas or seafood, although the certain source of infections was indeterminate. The investigation suggests that in addition to coastal areas, Shewanella as a potential pathogen at inland areas should not be ignored.

Shewanella species in the two cases were primarily identified as $S$. algae and S. putrefaciens by VITEK 2 system using the ID-GN card (boiMérieux), and then were confirmed as S. haliotis and S. upenei by $16 \mathrm{~S}$ rRNA sequence analysis. This misidentification has also been reported in other studies. A retrospective investigation of Shewanella bacteremia in patients with hepatobiliary disease from Taiwan, China indicated that, five out of nine Shewanella strains were confirmed as the $S$. haliotis using $16 \mathrm{~S}$ rRNA sequencing analysis [11]. Byun JH et al. [26] reported 19 strains which were identified as $S$. algae by using VITEK 2 and Matrix-assisted laser desorption/ ionization time-of-flight (MALDI-TOF) mass spectrometry, whereas $16 \mathrm{~S}$ rRNA analysis identified 10 isolates as $S$. algae and 9 isolates as $S$. haliotis. The reason is that only two Shewanella species, S. putrefaciens and S. algae were registered in the database of VITEK 2 system and MALDI-TOF mass spectrometry. Therefore, to identify Shewanella at species level, it should also include the $16 \mathrm{~S}$ rRNA gene sequence analysis. With the surveillance of Shewanella species, we speculate that more Shewanella species in related to the clinical infections will be reported except for the species cited above such as $S$. upenei reported in this study. It is not yet known whether the pathogenicity and severity of the infections are inconsistent with different species of Shewanella, therefore, it is an urgent call for surveillance and control activities against Shewanella infections.

\section{Additional file}

Additional file 1: Table S1. Shewanella species and GenBank accession numbers of $16 \mathrm{~S}$ rRNA gene sequences of the black triangle in Fig. 1. (DOC $62 \mathrm{~kb}$ )

\section{Abbreviations}

BALF: Bronchoalveolar lavage fluid; MALDI-TOF: Matrix-assisted laser desorption/ionization time-of-flight; MIC: Minimal inhibitory concentration

\section{Funding}

The design of the study and collection of samples were supported by the NSFC of China (31570134). The analysis and interpretation of data and the manuscript writing were supported by the Priority Project on Infectious Disease Control and Prevention from the Ministry of Health, China (2012ZX10004215 and 2017ZX10104002).

\section{Availability of data and materials}

The 165 rRNA gene sequence of the two strains in this study had been deposited at DDBJ/ENA/GenBank under the accession numbers of MF589233 (https://www.ncbi.nlm.nih.gov/nuccore/MF589233) and MF589234 (https:// www.ncbi.nlm.nih.gov/nuccore/MF589234).

\section{Authors' contributions}

Designed the work: DCW, BK, JGX, JXZ; Performed the experiments: YJF, SNL, $X$ L; Collection sample and isolation strains: FRZ, SNL, FP, YJD; Analyzed the data: YJ F, DCW, FP; Wrote the paper: YJF, DCW. All authors read and approved the final manuscript.

Ethics approval and consent to participate Not applicable.

\section{Consent for publication}

Written informed consents were obtained from the patient (case 1) and patient's direct relative (case 2) for publication of this study. 


\section{Publisher's Note}

Springer Nature remains neutral with regard to jurisdictional claims in published maps and institutional affiliations.

\section{Author details}

'Liaocheng Center for Disease Control and Prevention, Liaocheng, People's Republic of China. ${ }^{2}$ State Key Laboratory of Infectious Disease Prevention and Control, National Institute for Communicable Disease Control and Prevention, Chinese Center for Disease Control and Prevention, Beijing 102206, People's Republic of China. ${ }^{3}$ Collaborative Innovation Center for Diagnosis and Treatment of Infectious Diseases, Hangzhou 310003, People's Republic of China. ${ }^{4}$ Center for Human Pathogen Collection, Chinese Center for Disease Control and Prevention, Beijing 102206, People's Republic of China. ${ }^{5}$ Department of Clinical Laboratory, Qilu Hospital of Shandong University, Jinan 250012, People's Republic of China. ${ }^{6}$ Department of Clinical Laboratory, Liaocheng People's Hospital, Liaocheng 252000, People's Republic of China.

Received: 5 October 2017 Accepted: 22 August 2018

Published online: 05 September 2018

\section{References}

1. Poovorawan K, Chatsuwan T, Lakananurak N, Chansaenroj J, Komolmit P, Poovorawan Y. Shewanella haliotis associated with severe soft tissue infection, Thailand, 2012. Emerg Infect Dis. 2013;19(6):1019-21.

2. Zong Z. Nosocomial peripancreatic infection associated with Shewanella xiamenensis. J Med Microbiol. 2011;60(9):1387-90.

3. Vignier N, Barreau M, Olive C, Baubion E, Theodose R, Hochedez P, Cabie A. Human infection with Shewanella putrefaciens and S. Algae: report of 16 cases in Martinique and review of the literature. Am J Trop Med Hyg. 2013; 89(1):151-6.

4. Lane DJ. 16S/23S rRNA sequencing. In: Stackebrandt E, Goodfellow M, editors. Nucleic Acid Techniques in Bacterial Systematics. New York: Wiley; 1991. p. 115-75

5. Caporaso JG, Lauber CL, Walters WA, Berg-Lyons D, Lozupone CA Turnbaugh PJ, Fierer N, Knight R. Global patterns of $16 S$ rRNA diversity at a depth of millions of sequences per sample. Proc Natl Acad Sci U S A. 2011; 108(1):4516-22.

6. Hess M, Sczyrba A, Egan R, Kim TW, Chokhawala H, Schroth G, Luo S, Clark DS, Chen F, Zhang T, et al. Metagenomic discovery of biomass-degrading genes and genomes from cow rumen. Science. 2011;331(6016):463-7.

7. Goyal R, Kaur N, Thakur R. Human soft tissue infection by the emerging pathogen Shewanella algae. J Infec Dev Ctries. 2011;5(4):310-2.

8. Pagani L, Lang A, Vedovelli C, Moling O, Rimenti G, Pristera R, Mian P. Soft tissue infection and bacteremia caused by Shewanella putrefaciens. J Clin Microbiol. 2003:41(5):2240-1.

9. Rouzic N, Hery-Arnaud G, Jaffuel S, Garo B, Payan C, Garre M. Pathol-Biol. 2012;60(3):e27-9.

10. Dominguez H, Vogel BF, Gram L, Hoffmann S, Schaebel S. Shewanella alga bacteremia in two patients with lower leg ulcers. Clin Infec Dis. 1996;22(6):1036-9.

11. Liu PY, Lin CF, Tung KC, Shyu CL, Wu MJ, Liu JW, Chang CS, Chan KW, Huang JA, Shi ZY. Clinical and microbiological features of shewanella bacteremia in patients with hepatobiliary disease. Intern Med. 2013;52(4):431-8.

12. Janda JM, Abbott SL. The genus Shewanella: from the briny depths below to human pathogen. Crit Rev Microbiol. 2014;40(4):293-312.

13. Wang D, Wang $Y$, Huang $H$, Lin J, Xiao D, Kan B. Identification of tetrodotoxin-producing Shewanella spp. from feces of food poisoning patients and food samples. Gut pathogens. 2013;5(1):15.

14. To KK, Wong SS, Cheng VC, Tang BS, Li IW, Chan JF, Seto WK, Tse H, Yuen KY. Epidemiology and clinical features of Shewanella infection over an eight-year period. Scand J Infect Dis. 2010;42(10):757-62.

15. Liao WY, Liaw YS, Wang HC, Chen KY, Luh KT, Yang PC. Bacteriology of infected cavitating lung tumor. Am J Respir Crit Care Med. 2000;161(5):1750-3.

16. Jorens PG, Goovaerts K, leven M. Shewanella putrefaciens isolated in a case of ventilator-associated pneumonia. Respiration. 2004;71(2):199-201.

17. Tucker C, Baroso G, Tan P. Ventilator-associated pneumonia due to Shewanella putrefaciens. Am J Health Syst Pharm. 2010;67:1007-9.

18. Chen YS, Liu YC, Yen MY, Wang JH, Wann SR, Cheng DL. Skin and softtissue manifestations of Shewanella putrefaciens infection. Clin Infect Dis. 1997;25(2):225-9.
19. Kim D, Baik KS, Kim MS, Jung BM, Shin TS, Chung GH, Rhee MS, Seong CN Shewanella haliotis sp. nov., isolated from the gut microflora of abalone, Haliotis discus hannai. Int J Syst Evol Microbiol. 2007;57(12):2926-31.

20. K T AS, K O DM, J S TM. A case report of Shewanella haliotis showing a phlegmonous inflammation of right lower leg with sepsis. JSCM. 2010;20:239-44.

21. Tena D, Losa C, Carrasco G, Sáez-Nieto JA. Cellulitis caused by Shewanella haliotis Case Report and Literature Review. Infect Dis Clin Pract. 2016;24:76-8.

22. Takata T, Chikumi H, Morishita S, Hamada S, Hoi S, Iyama T, Fukui T, Matono T, Fukuda S, Munemura C, et al. Shewanella algae bacteremia in an endstage renal disease patient: a case report and review of the literature. Intern Med. 2017:56(6):729-32.

23. Krsnik I, Arribalzaga K, Romanyk J. Shewanella alga bacteremia and associated cellulitis in a patient with multiple myeloma. Haematologia. 2002;32(1):79-80.

24. Lee WS, Ou TY, Chen FL, Hsu CW, Jean SS. Shewanella putrefaciens bacteremia in a uremic patient receiving hemodialysis. J Microbiol, Immunol Infect. 2016;49(1):159-60.

25. Kim KK, Kim YO, Park S, Kang SJ, Nam BH, Kim DN, Oh TK, Yoon JH. Shewanella upenei sp. nov., a lipolytic bacterium isolated from bensasi goatfish Upeneus bensasi. J Microbiol. 2011;49(3):381-6.

26. Byun $\mathrm{JH}$, Park $\mathrm{H}$, Kim S. The phantom menace for patients with hepatobiliary diseases: Shewanella haliotis, often misidentified as Shewanella algae in biochemical tests and MALDI-TOF analysis. Jpn J Infect Dis. 2017;70(2):177-80.

27. Holt HM, Gahrn-Hansen B, Bruun B. Shewanella algae and Shewanella putrefaciens: clinical and microbiological characteristics. Clin Microbio infect. 2005;11(5):347-52.
Ready to submit your research? Choose BMC and benefit from:

- fast, convenient online submission

- thorough peer review by experienced researchers in your field

- rapid publication on acceptance

- support for research data, including large and complex data types

- gold Open Access which fosters wider collaboration and increased citations

- maximum visibility for your research: over $100 \mathrm{M}$ website views per year

At BMC, research is always in progress.

Learn more biomedcentral.com/submission 